\title{
Exciting Technique for MSA Array By Using Single Patch With Surrounded Metallic Plate
}

\author{
Warakorn Sarikha \\ School of Telecommunication, \\ Institute of Engineering, \\ Suranaree University of Technology, \\ NakhonRatchasima, Thailand \\ E-mail: D5540075@g.sut.ac.th
}

\author{
Piyaporn Krachodnok \\ School of Telecommunication, \\ Institute of Engineering, \\ Suranaree University of Technology, \\ NakhonRatchasima, Thailand \\ E-mail:priam@sut.ac.th
}

\author{
Rangsan Wongsan \\ School of Telecommunication, \\ Institute of Engineering, \\ Suranaree University of Technology, \\ NakhonRatchasima, Thailand \\ E-mail:rangsan@sut.ac.th
}

\begin{abstract}
Abstract- This paper presents the study of new technique for exciting the $4 \times 4$ rectangular microstrip patches antenna (MSA) array by using a single patch, which is surrounded with metallic plate. The objective of this research is to explore the new technique for exciting any microstrip array instead of the conventional phasing line that have energy loss and narrow bandwidth occurred inside it. From many literatures, we found that the single patch of rectangular MSA can directly excite to them and reradiated to the free-space. However, if this patch is surrounded by metallic plate on the same layer, its gain can be increased more than using only single patch excited it. The exciting patch with surrounded metallic plate has been designed by using general $\mathrm{PCB}$, which has the dielectric constant, equals to 2.2. While the $4 \times 4$ MSA array is designed by using FR4PCB with dielectric constant equals to 4.4. The substrate thicknesses of both types of PCB are $1.6 \mathrm{~mm}$. From the simulated results by using the licensed Computer Simulation Technology (CST) software, we found that the gain of antenna can be raised up from $11.68 \mathrm{~dB}$ (without metallic surrounded plate) to $13.42 \mathrm{~dB}$ at $10 \mathrm{GHz}$ operating frequency. However, the required radiation patterns of MSA array antenna can be adjusted by using the general theoretical technique.
\end{abstract}

\section{Keywords-MSA Array; Antenna Gain; Exciting Patch}

\section{INTRODUCTION}

The microstrip patch antenna was developed a long time ago. It was the basic structural features as small uncomplicated and inexpensive, which can be applied to both low frequency and high frequency (by select the type of substrates or adapt dimension). Therefore, developers or researchers commonly used this kind of antennas in many wireless applications[1][2][3][4]. Generally, the gain of MSA is increased by combining many patches, which fabricated on PCB, to work together that so-called MSA array and connected each of them together with phasing line on the same layer of patches[5][6][7]. The disadvantage of this conventional feeding method, not only occur energy loss inside these lines, but also the frequency bandwidth that flow through this phasing line will be limited.

The conventional directed feeding techniques for MSA array in the past, especially, by using phasing lines and were connected with the coaxial feeder as referred in [1], [3],
[5],[7], will encounter to the energy losses in the phasing lines of array, consequently, the radiation efficiency of such antenna is low. Therefore, the main point of this paper is the effort to investigate the new technique for decreasing the energy losses and increasing the radiation efficiency due to phasing lines but still retain the radiation characteristics of MSA array by using the directed coupling technique.

In this paper, we have presented the new exciting method for MSA array instead of the phasing lines that ever used in the past. For the initial concept, the structure of rectangular MSA array on FR4-substrate without metallic ground plane will be independently separated from exciting system, which is located under the MSA array layer with the appropriated distance. The structure of new feeding or exciting system has been designed on the general PCB that is used for electronic circuits. Its structure still be similar to the generally single microstrip antenna that consists of radiating patch, dielectric substrate and ground plane. While the dimension of this patch is calculated on the basic of single patch microstrip antenna [8]. The additional component of this paper is the metallic plate that is added on the top of dielectric substrate, which the radiating patch is located on. However, this metallic plate will be spaced like as the rectangular-ring slot surrounded this exciting patch and this spacing will be adjusted for impedance matching at the resonant frequency.

To verify this concept, the $4 \times 4$ elements of rectangular MSA array without metallic ground plane is designed, at $10 \mathrm{GHz}$ resonant frequency. This MSA array is located over the exciting part with the appropriated spacing between them as mentioned before. The simulated results will be calculated by using Computer Simulation Technology (CST) software. Especially, its gain is compared between the exciting patch with surrounded metallic plate and without one.

At first, the structure of the exciting system by using single radiating patch with surrounded metallic plate and the $4 \times 4$ elements of rectangular MSA array will be mentioned in the Section II. Next, the simulated results of this antenna will be calculated by CST software and mentioned in the Section III together with the discussion. Finally, the conclusion will be given in the Section IV. 


\section{STRUCTURE DESIGN}

\section{A. Exciting patch with surrounded metallic plate}

The dimension of single patch antenna was designed with the width $\left(\mathrm{w}_{\mathrm{f}}\right)$ is $7.155 \mathrm{~mm}$ and length $\left(\mathrm{l}_{\mathrm{f}}\right)$ is $9.079 \mathrm{~mm}$ and placed on the common PCB with dielectric constant is 2.2 and is fed by a probe connected the $50 \Omega$-SMA connector. The surrounded metallic plate is located on the top of dielectric substrate. The spacing gap $\left(\mathrm{g}_{\mathrm{s}}\right)$ between the exciting patch and metallic plate is specified at $1.5 \mathrm{~mm}$ as shown in Fig.1.

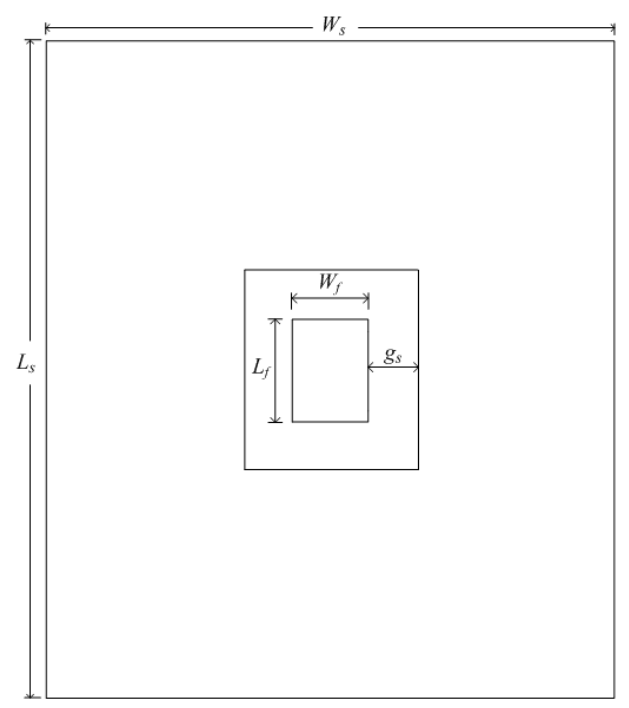

Fig. 1. Geometry of exciting patch with surrounded metallic plate.

\section{B. $4 x 4$ elements of rectangular MSA Array}

The $4 \times 4$ rectangular MSA array was designed and placed on the top of FR-4 PCB with dielectric substrate equals to 4.4 and its thickness is $1.6 \mathrm{~mm}$. The spacing between adjacent elements of the patches is specified with $d_{1}=d_{2}$. The dimension of the patch is calculated as follow: the width $\left(\mathrm{W}_{\mathrm{p}}\right)=5.5 \mathrm{~mm}$, length $\left(\mathrm{L}_{\mathrm{p}}\right)=7.5 \mathrm{~mm}$ and the element spacing between the adjacent element $\left(\mathrm{d}_{1}\right)$ equals to $7.5 \mathrm{~mm}$. The width $\left(\mathrm{W}_{\mathrm{s}}\right)$ and length $\left(\mathrm{L}_{\mathrm{s}}\right)$ of FR4 substrate are $78 \mathrm{~mm}$ and $78 \mathrm{~mm}$, respectively, as shown in Fig.2.

\section{RESULT AND DISCUSION}

To verify the conceptual design of this paper, the licensed CST software of our laboratory has been used to simulate the gain of SMA array antenna with the surrounded metallic plate compared to without one. The element spacing between adjacent elements $\left(d_{1}=d_{2}\right)$ and the distance $(h)$ between layers of MSA array part and exciting part were optimal adjusted in CST software for the best performance of gain and radiation pattern. Form the simulated results, we found that the optimized distances of $\mathrm{d} 1$ and $\mathrm{h}$ are $11.25 \mathrm{~mm}$ and $15 \mathrm{~mm}$ respectively. The simulated results in Fig.3 (a) and (b) show the radiation patterns and Half-power Beamwidth (HPBW) of the $4 \times 4$ rectangular SMA array antenna, which is directly excited with single patch, while Fig.3 (c) and (d) show the radiation patterns of SMA array, which is excited with the proposed excitation technique. We found that the HPBW of E-plane pattern in Fig.3(c) is around 25.2 degrees, which is narrower than HPBW (approx. 26.4 degrees) in Fig.3(a), while, the patterns comparison in Fig. 3(b) and (d), the HPBW of H-plane patterns in case of the SMA array antenna is excited by the new one is around 19.8 degrees and 23.9 degrees, respectively. However, the directive gain of the first and the second one is around $11.68 \mathrm{~dB}$ and $13.42 \mathrm{~dB}$, respectively. Show that the $4 \times 4$ MSA array antenna excited by single patch with surrounded metallic plate can provide the higher directive gain, as shown in Fig.4.

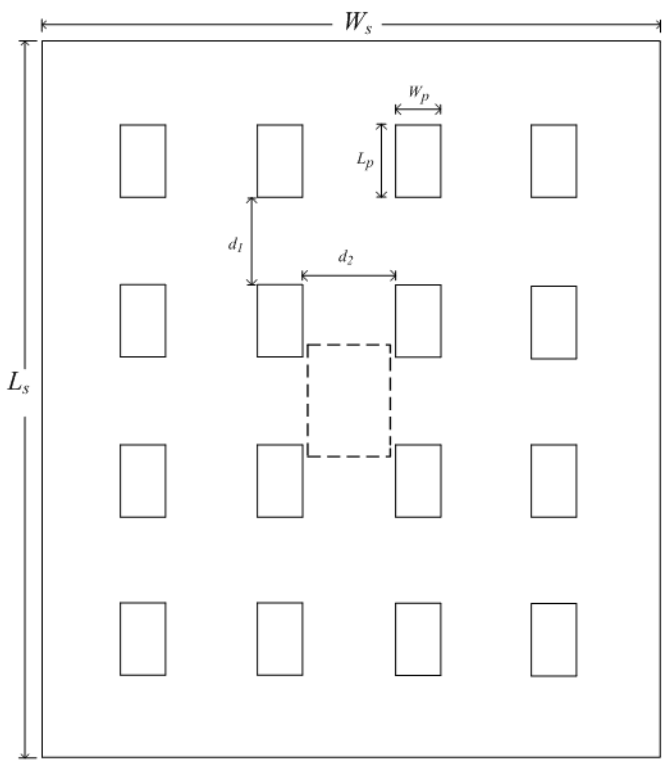

(a) Top View

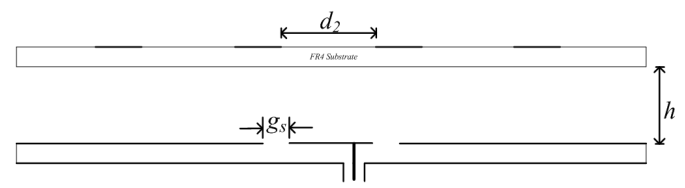

(b) Side View

Fig. 2. Structure of the proposed antenna with the exciting system (a) $4 \times 4$ rectangular MSA array (b) MSA array antenna with the exciting system. 


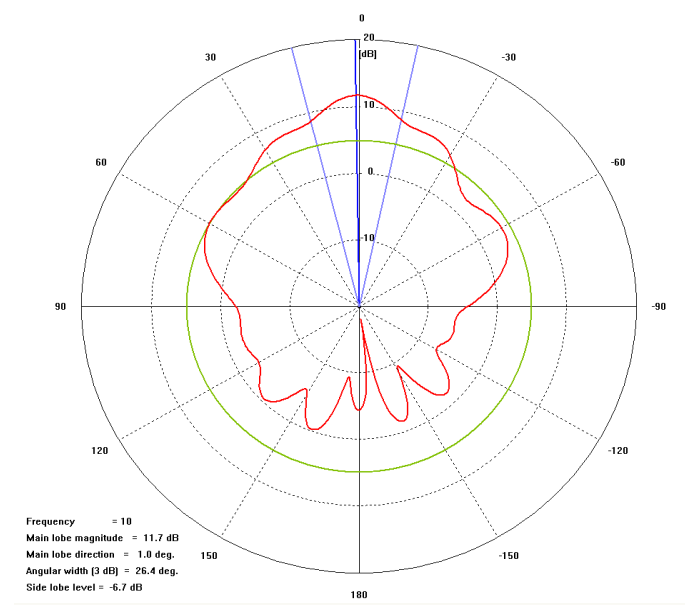

(a) E-plane pattern (without surrounded plate)

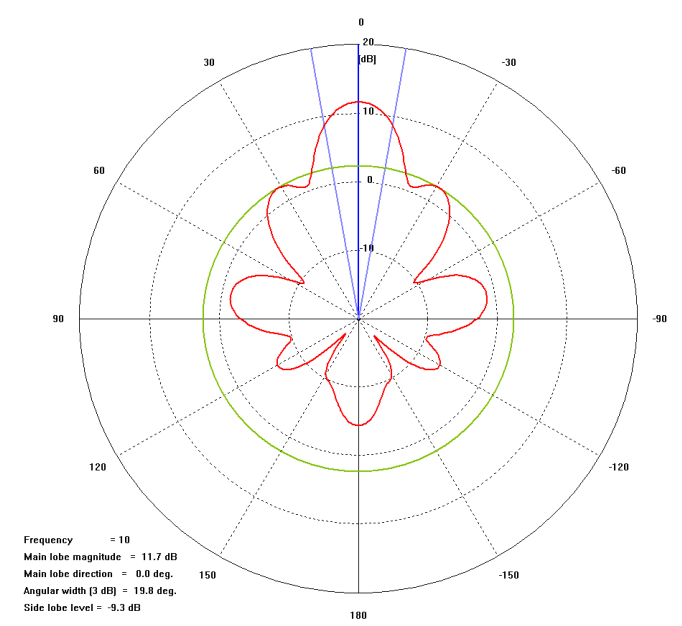

(b) H-plane pattern (without surrounded plate)

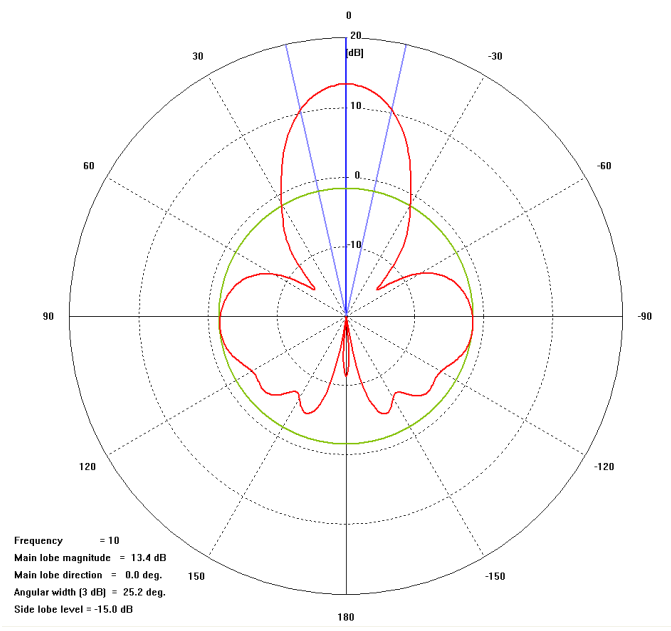

(c) E-plane pattern (with surrounded plate)

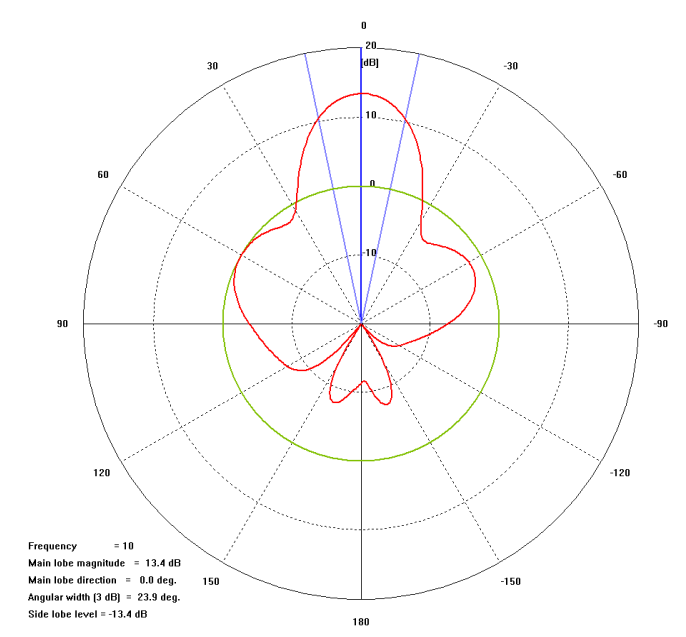

(d) H-plane pattern (with surrounded plate)

Fig. 3. Radiation Pattern of $4 \times 4$ MSA array excited by single patch without and with surrounded metalic plate.

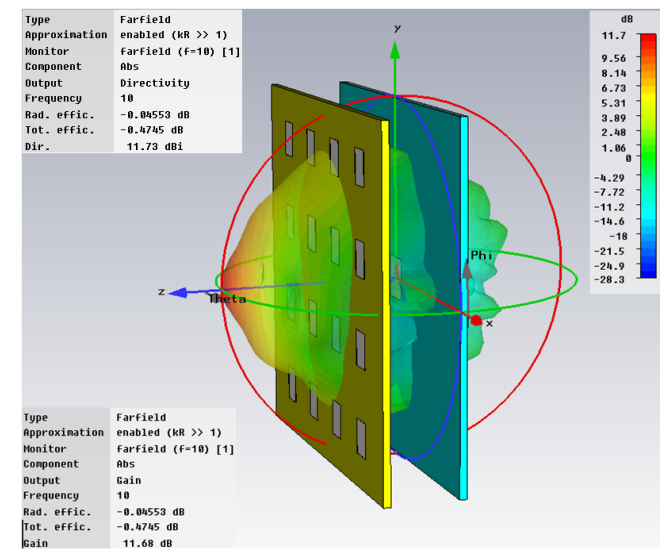

(a) 3D pattern (without surrounded plate)

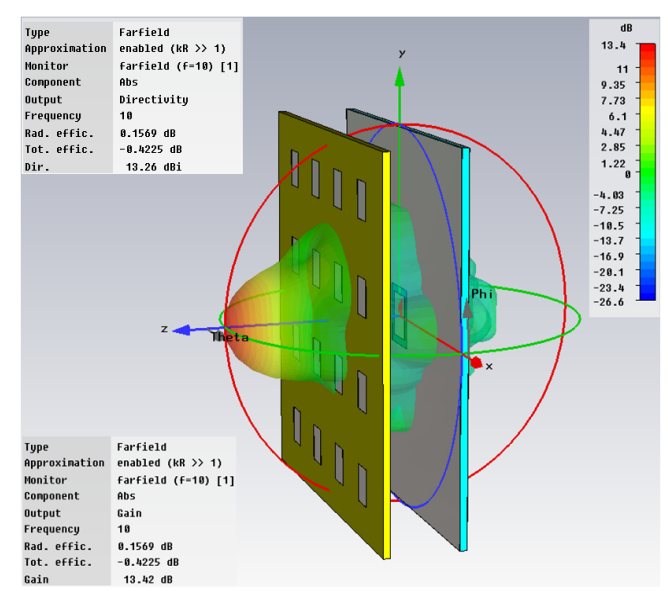

(b) 3D pattern (with Surrounded plate)

Fig. 4. Perspective view of structure and pattern in case of: (a) without surrounded metallic plate (b) with surrounded metallic plate 


\section{CONCOSTION}

To verify the conceptual design of this paper, the licensed The $4 \times 4$ elements of MSA array excited by the single radiating patch with surrounded metallic plate was proposed. The simulated results of radiation patterns calculating by using CST software evidently show that just adding the metallic plate on the top of dielectric substrate and surround the radiating patch can provide the higher directive gain when compare to gain of MSA array antenna which directly excited from the single patch alone. Although the yielding gain is not so much, but it can be predicted that the trend of this excitation technique has the possibility to substitute the conventional exciting with phasing lines. However, this paper has presented only the simulated results and still have some parameters that will be studied for the best performance and dimension. Finally, the antenna prototype will be fabricated and reported the measured results in the next opportunity.

\section{ACKNOWLEDGMENT}

This work was support by the Research Department Institute of Engineering, Suranaree University of Technology. Nakhonratchasima, Thailand.

\section{REFERENCES}

[1] K.K. Singh, S.C.Gupta, "Review and analysis of microstrip patch array antennar with difference configurations", International Journal of scientific \& engineering research, vol.4 issue 2, 2013.

[2] K.S. Beenamole, "Microstrip Antenna Designs for Radar Applications" DRDO Science Sepctrum,pp. 84-86, March 2009.

[3] K.Shambavi, Z.Alex, T.Naveen phani krisha, "Design and analysis of high gain millimeter wave microstrip antennar array for wirless applications", Journal of theotical and applied information technology, 2005-2009.

[4] M. K. A. Rahim', A. Asrokin1, M. H. Jamaluddin1, M. R. Ahmad1, T. Masril and M. Z.A. Abdul Aziz2, "Microstrip Patch Antenna Array at $5.8 \mathrm{GHz}$ for Point to Point Communication", International rf and microwave conference proceedings, September 12 - 14, 2006.

[5] M.Liu, F.Y.Meng, F.L.Sun, Q.Wu, “A 35ghz cone conformal microstrip 4x4 array", Proceeding of asia-pacific microwave conferrence, 2007.

[6] M.T. Zhang, Y.C. Jiao, F.S.Zhang and W.T.Wang,"Design of Antennas for RFID Application",Development and Implementation of RFID Technology, Book edited by: Cristina TURCU, ISBN 978-3-902613-547, pp. 554, February 2009

$$
\text { Technology (JATIT), } 2009 .
$$

[7] T. I.Hugue, A.A. Chowdhury, K. Hosain, S.Alam,"Performance analysis of corperate feed rectangular patch element and circular patch feed rectangular patch element and circular patch element $4 \times 2$ microstrip array antennas", International journal of advanced computer science and applications, vol.2, No. 8, 2011.

[8] R. Bancroft,"Microstrip and Printed Antenna Degign", SciTech Publishing, Inc. 